$5^{\text {th }}$ International $/ 11^{\text {th }}$ Construction Specialty Conference

$5^{e}$ International $/ 11^{e}$ Conférence spécialisée sur la construction

Vancouver, British Columbia

June 8 to June 10, 2015 / 8 juin au 10 juin 2015

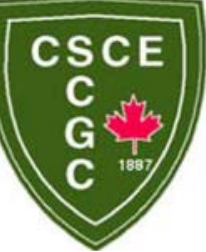

\title{
DESIGN CHANGE MANAGEMENT USING A BIM-BASED VISUALIZATION MODEL
}

\author{
Valeh Moayeri ${ }^{1}$, Osama Moselhi ${ }^{1}$ and Zhenhua Zhu ${ }^{1}$ \\ ${ }^{1}$ Civil \& Environmental Engineering, Concordia University, Montréal, Québec, Canada \\ 2 valeh.moayeri@gmail.com
}

\begin{abstract}
Building projects frequently experience a number of changes in design development to satisfy owners' space and functional needs within allocated budgets. These iterative changes, while necessary, individually and collectively have ripple effect on what appears to be the unchanged scope of projects work, with varying impacts on project delivery time and cost. Efficient management of design changes requires scope rendition and minimization of time and cost impacts of these changes. This paper presents an automated model, developed to help design professionals and owners visualize the ripple effect of contemplated design changes. This visualization covers those design changes requested by owners after completion of the design phase and before commencement of the construction phase. The developed model is expected to help owners and their agents to better grasp the ripple effect of design changes and consequently, to make better decisions as to approving or rejecting contemplated changes. The model is also able to calculate the impact of changes on projects cost and time. The model is developed on the basis of comparing the original model of a building to its revised model, which incorporates the introduced changes. The changes included in the developed model encompass addition, deletion as well as changes in quantities and specifications of building components. The model is then integrated with Building Information Modeling (BIM) to provide visualization and documentation of the design changes. The use of BIM provides significant benefits in coordinating changes across different views in the model, thereby enabling users to study the ripple effect of a change from different views, such as plans, elevations and 3D views. The model is capable of illustrating the ripple effect in architectural, mechanical, electrical and HVAC systems. For evaluation purposes, the model has been applied to a case study.
\end{abstract}

\section{INTRODUCTION}

Owners of construction projects have become more and more demanding, continuously changing their project's design to suit their evolving needs, particularly in non-traditional project delivery systems. They may request changes at any phase of a project to respond to new market demands (Ibbs, 2012). Almost 20 years ago, studies had revealed that $20-25 \%$ of the construction period was lost as a result of inadequate design (Undurraga, 1996). In addition, lower-quality construction was attributed in $78 \%$ of projects to percentage of design changes (Koskela, 1992).

A change is any additional work added to the scope of a project that causes the project to incur delays and/or additional costs to the original contract. As such, a change can take many forms. However, it is owner-initiated change that must receive more attention than any other types of change, as this sort of change could present a risk to both the owner and the contractor. A change may be simple in an owner's 
mindset, but that perspective (most likely) does not consider the multiple affects that one change can have on many other areas of a project. Each change could add to the cost of the original contract and/or cause a delay in the project's execution, even though there could be cases where a change does not add to a project's cost and time. Some changes can even be beneficial to both owner and the contractor, but that situation is rather rare. A system that can manipulate changes would thus be a valuable tool in the construction industry. Owners should be involved in their projects, and the role and responsibility of an AEC (Architectural, Engineering, and Construction) team is to provide guidance, giving the owner all the required information about the requested change and its impacts on the project. If this new system could visualize the change and illustrate its impacts, then the owner would be able to see the 'big picture' and make an informed decision. This system should avoid unnecessary conflicts and disputes between the owner and the contractor, and thus greatly reduce the recourse to lawsuits.

A successful management system for applying, visualizing, analyzing and organizing change orders requested by owners would clearly be beneficial. Dealing with change orders in the traditional fashion, using paper-based printouts of $2 \mathrm{D}$ drawings, is no longer adequate, as it does not allow all of the ramifications of a change to be discovered. Moreover, with projects becoming increasingly complex, the ripple effect analysis of design changes is becoming much more challenging and time-consuming. This problem is being addressed by the development of Building Information Modeling (BIM) to provide realtime dynamic databases. BIM makes it possible to apply a change to a building model and to determine the impacts of that change in the design model, in every view and in real time. In other words, it can selfadjust a model's database whenever a new change is applied. However, the user is only able to see a change, and the newly-affected model, but not the ripple effect of that change. BIMs only visualize the new model design; they do not highlight the components that are affected by the changed component(s). This limitation illustrates the need to develop a BIM-based change management system to provide effective management of a multi-disciplinary model through the dynamic procedure of building design. This study presents an integrated BIM-based automated model for design professionals and owners. It is designed to improve the visualization capabilities to help in analyzing a change's ripple effect and in tracking the consequences, and to help owners and designers to communicate with each other in selecting beneficial changes that respond to the owners' desired criteria, prior to the construction phase.

\section{BACKGROUND}

Understanding the meaning of change management is as important as knowing its process. Voropajev (1997) defined it as "an integral process related to all project's internal and external factors influencing project changes: any possible change forecast; the identification of already-occurred changes; planning preventive impacts; to the coordination of changes across the entire project" (Voropajev, 1997). Tiong (1990) said, "a change order management system should be established for the ultimate benefit of owners" (Tigon, 1990). Sun et al. (2006) stated "the aim of project change management is not to seek the elimination of all project changes, but to minimize the negative impact of necessary changes and to avoid unnecessary ones" (Ming Sun A. F., 2006). Mirshekarlou (2012) reported that "by implementing a project change management system, a project's involved parties would be able to reduce deleterious changes and encourage beneficial changes. Also, the project's work performance and its chance of success should increase" (Mirshekarlou, 2012).

A change order process can be qualitative or quantitative, and sometimes a system can be a combination of both. Both systems would help the project participants to have a bright outlook on the possible changes and their impacts. Qualitative methods focus on how to process change orders once a change request is made, and how to make it beneficial for both the owner and the contractor. All the available best practices, guidelines and change management process steps can be classified as quantitative methods. These steps guide the change management process from the time the change is initiated to the completion of the project. However, there is no guaranty that a project will benefit, as none of these qualitative methods can identify the ripple effect of the changes that result from a single change. Current industry practice uses this type of change management process. To identify a changes' ripple effect, experts must go through the all of a systems' 2D printouts to see if the change could cause ripple effect in other parts of the project. This is very time-consuming and requires a number of highly-experienced 
experts to use their knowledge to identify the change consequences. On the other hand, there are many quantitative methods that can be used to study the impact of changes. Quantitative methods concentrate on the impacts of the change order on time, cost, quality and/or productivity, and calculate everything numerically. All of the theoretical models and information models can be utilized in the quantitative change management system.

The first leaders in quantitative models were Leonard et al. (1991); utilizing the data from 57 different construction projects, they developed a regression model to quantify the impact of change orders on productivity (Leonard, 1991). Mokhtar et al. (1998) implemented an information model to help project participants coordinate design information when design changes occur by using a central database that of active building components. The model can transit design changes, track past changes, plan and schedule future changes and improve design change management (Mokhtar, 1998). Hanna et al. (2002) presented a new methodology, an integration of statistical regression and fuzzy logic, to quantify the cumulative impact of change orders on construction projects. The output of a fuzzy membership function would be the expected loss of labor productivity and its standard deviation (Awad S. Hanna. P. M.-J., 2002). Moselhi et al. (2005) developed a neural network model for quantifying the impact of change orders on labor productivity. The model is integrated with four other models, developed by others, to make a prototype software system that evaluates the percentage loss of labor productivity due to change orders (Osama Moselhi, 2005). Zhao et al. (2010) developed a change order prediction model as a beneficial tool for project management teams to manage changes proactively and efficiently. The model uses an activity-based dependency structure matrix (DSM) to identify the ripple effect of changes. It uses Monte Carlo simulation to analyze the change probability of activities involved in construction projects (Zhen Yu Zhao, 2010). Langroodi et al. (2012) evaluated existing BIM tools through a case study to determine if how BIM could be capable of aiding change management during the design and construction of fast-track projects. An ontology for change was developed in order to provide a common understanding of change characteristics for those when using BIM to manage changes (Behzad Pilehchian Langroodi., 2012). Most of the current quantitative models are designed to calculate the impact of change on productivity. Some of them are only applicable to the mechanical and electrical aspects of projects. These do not have any computer implementation and their limited number of variables reduces their practical utilization. None of them is able to visualize the ripple effect of the changes.

\section{PROPOSED METHODOLOGY}

This paper introduces a BIM-based model to support design change management; particularly to visualize the ripple effect of design change. Integration and automation methods were applied to the model development process to support change management. The main purpose behind the developed model is to provide decision makers with a tool to visualize the ripple effect of owner-requested design changes.

The process of project design change management begins when the owner requests design changes after completion of the design phase and before commencement of the construction phase. The design change is divided into four different categories: adding, removing and modifying one or more components in the original model, as well as any combination of these categories. These changes have their unique ripple effect on a project.

The developed model consists of three main frameworks, utilized for change management and owner decision-making. The first is a data acquisition framework, the second is a data analysis framework, and the third is a reporting framework as it is illustrated in Figure 1. 


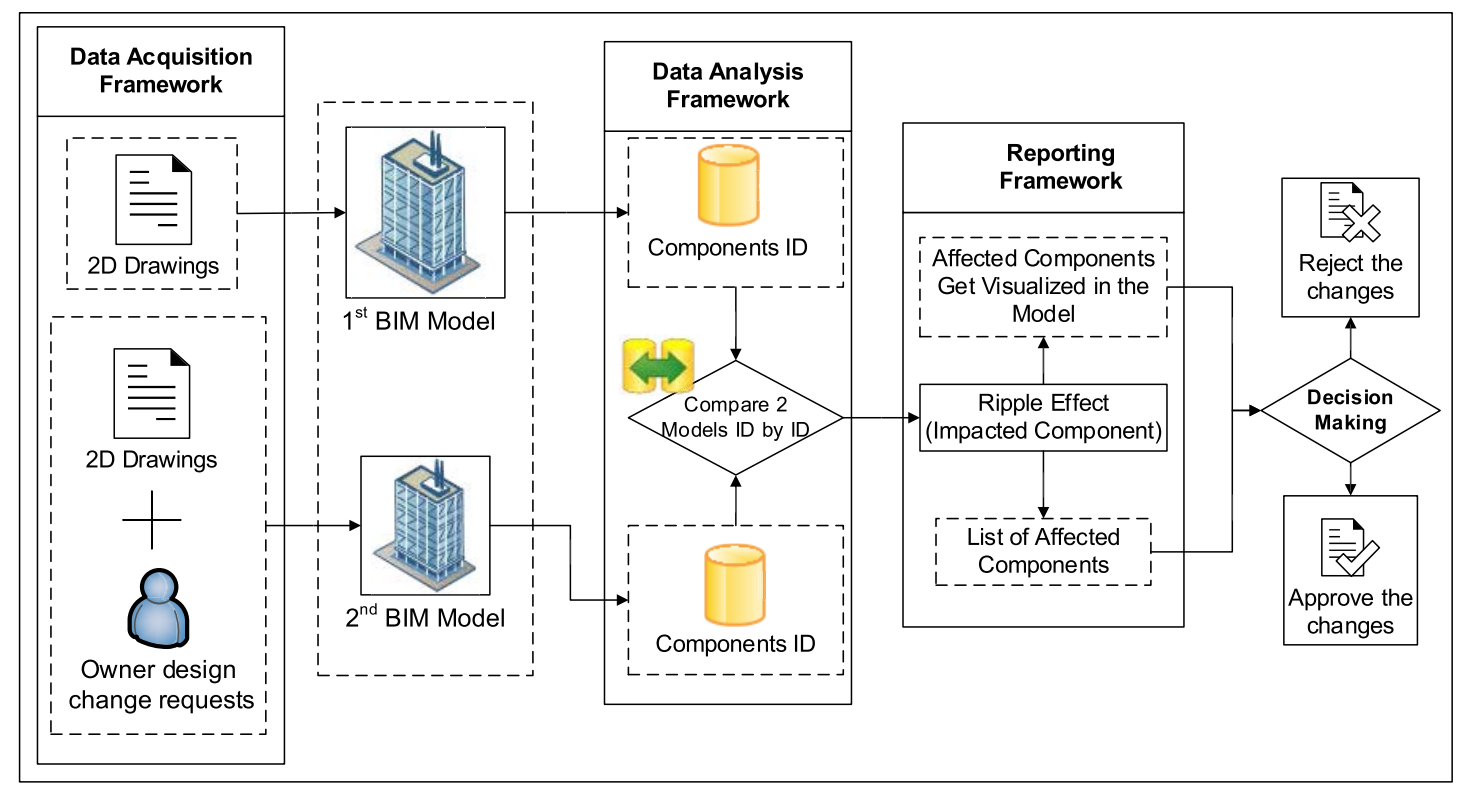

Figure 1: Proposed Methodology

\subsection{Data acquisition framework}

For data acquisition, the project 2D drawings are needed in order to generate the original 3D BIM model. For the purpose of change impact analysis, project systems, such as architectural, structural, electrical, mechanical, piping and plumbing and HVAC should be part of the BIM model. The other required data are the owner's design change requests. All requests are presented in a meeting with design team who applies them in the developed model in order to visualize their impact and share that with the owner. Meanwhile, the changes are introduced to a copy of the original 3D BIM model, which results in the creation of the $2 \mathrm{nd}$ model. The analysis is performed to trace the ripple effect of that change can begin.

\subsection{Data analysis framework}

In the data analysis framework the purpose is to visualize the ripple effect of an owner's design changes in all of a project's systems. By the time that a component has changed, the change may affect the other components that are connected to that first-changed component. Current BIM tools can update the whole model according to the first change. This means that when a change is happening in the attributes of a component, all the other components' attributes related or connected to the first-changed component will be adjusted automatically. The problem with this model fixation is that it is not easy to follow or to use to evaluate a subsequent improved design change analysis. This process gets even more complicated when a project is more complex, as there will be more components and attributes.

The developed model should be able to trace the relationship between the changed component and the other components that are connected to it, which means finding the change path or the change sequence. For example, a wall is attached to a window, a door, the roof, floor, etc. The component not only has a connection to the other architectural components, it also has a connection to the components of other systems, such as mechanical, electrical, HVAC, piping and plumbing.

Therefore, determining these relationships and connections is the main step involved in discovering the ripple effect of a change. In this model, work breakdown structure (WBS) is defined at a micro level in the scheduling, which means that every component in the model has its own data information. Having a micro WBS will ease this process. When a change occurs at a component level by having micro-level WBS, the model will detect the area that a changed component is located in. It will then detect all the components that are connected to the changed component to discover if there are any other changes occuring based on the first change, which is the main source of impact. This action will continue until there are no longer any changes being found in the other components in the architectural system or any other systems 
available in the model. The same procedure also occurs in the other areas that are connected to the area where the main change is located.

The proposed model begins the analysis of all the ripple effect by a comparison method, which means that the model starts to compare the original BIM model with the modified BIM model. The analyzing procedure is based on a component-by-component comparison between the two BIM models. Every component in both models has an ID, which simplifies the comparison, and the procedure will provide an immediate result. The comparison model will detect the following:

- If the components are found in one model but not in the other. This detection will be for those types of design changes where the owner decides to remove one or more component from the original model.

- If the components are found in both models, but the components' specification have changed in one model. This type of detection covers those types of design changes where the owner changes the specifications of one or more components in the original model.

- If the components are found in both models, and they have not changed from one model to the other.

\subsection{Reporting framework}

After the proposed model has visualized the change ripple effect, the next step is to provide a report to the user to assist in the change decision-making process. This model produces a report that shows all the affected components with their newly-assigned specifications such as length, height and width. The report also includes information about the original components, so that the user can see the differences between the original and the changed components. This report should be opened in the BIM interface and provide the visualization of the project model simultaneously, in a different window.

\section{CASE STUDY}

The proposed methodology is implemented and applied via BIM technology an actual project. In this study, the BIM platform is defined in Autodesk Revit 2014. The Revit.NET Application Programming Interface (API) allows users to program with any.NET compliant language, such as VB.NET and C\#, as a way to add extensions to the originally generated BIM model. The developed model is merged with plugins that are coded in Microsoft Visual C\#.Net programming language, which is in compliance with Revit APIs. The developed Revit add-In is named "Check Change". Check Change provides the user with a change order ripple effect visualization of the owner-requested design change(s). At the same time, it also provides a report of the change ripple effect and a list of all the components that would be changed as a result of the owner's change request(s).

In the data acquisition part, the BIM model is developed from the project's architectural drawings; this model is called the Original model. After generating the Original model, the user opens the second model, which is a copy of the original model and is called the Copy. The user then modifies the Copy model according to the owner's design change requirements. Both models will be shown in the same interface. Thus, the user can see both the Original and the Copy models in the Revit interface, as shown in figure 2. The program is designed so that the user cannot open more than two models at the same time. 


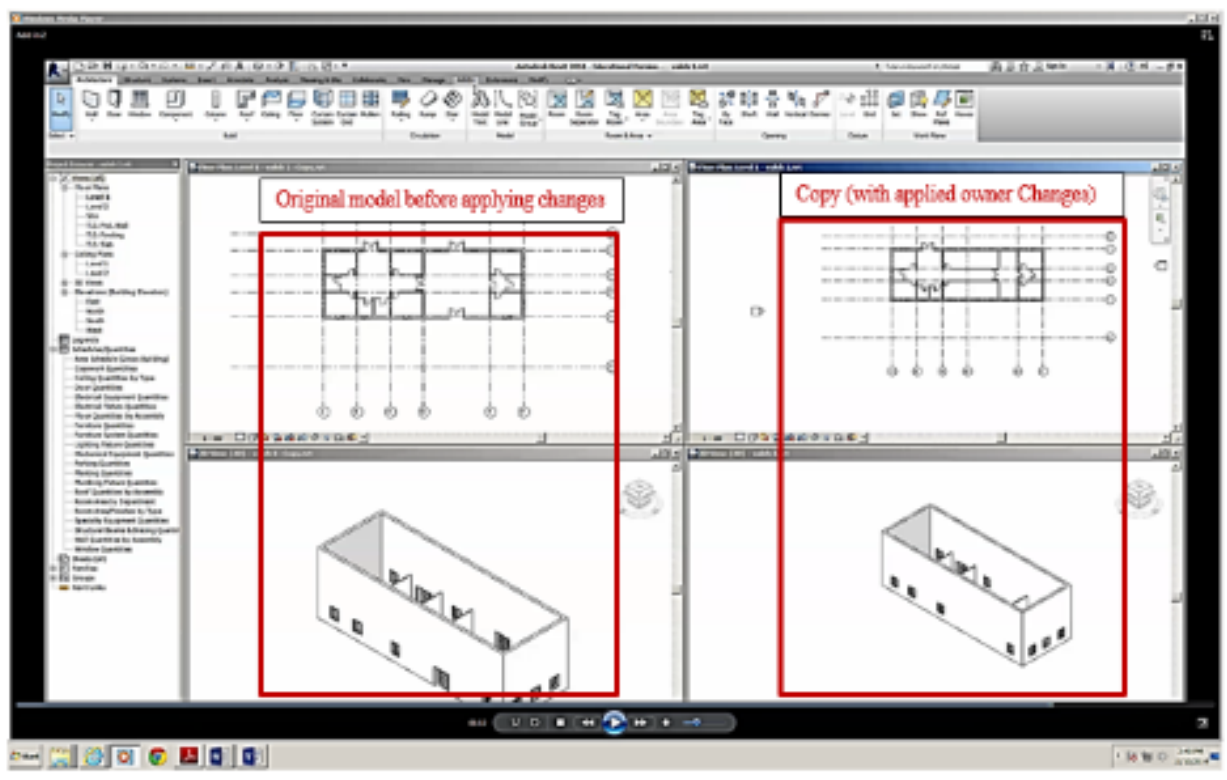

Figure 2: Architectural System Data Acquisition

The Revit program also provides the ability for the user to see the Original and the Copy models from different viewpoints, such as plan, elevation, and section and 3D views. Having this access to the different views improves and facilitates the visualization process and a more complete understanding of the design changes. After uploading the models in the Revit interface, the next step is to click on the Check Change add-In to visualize the change ripple effect, visualized when the coded Revit add-In starts to compare the Original and the Copy models to detect the differences between the two models' components. Clicking on Check Change tells the system to start the component-by-component comparison between the two models, as illustrated in Figure 3.

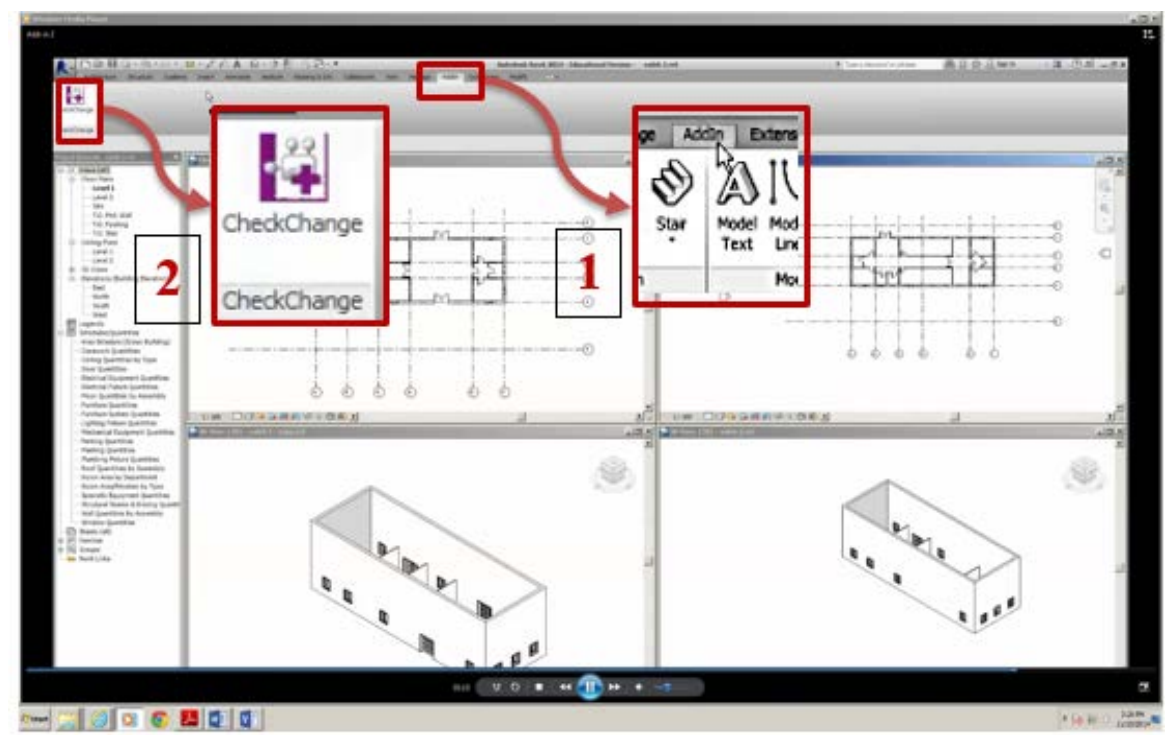

Figure 3: Revit Add-In (Check Change)

The visualization procedure is shown in Figure 4. At this stage of the model development, all of the visualization is shown in one color. Part of this study plan is to define different colors for the different results of the comparison between the two models. 


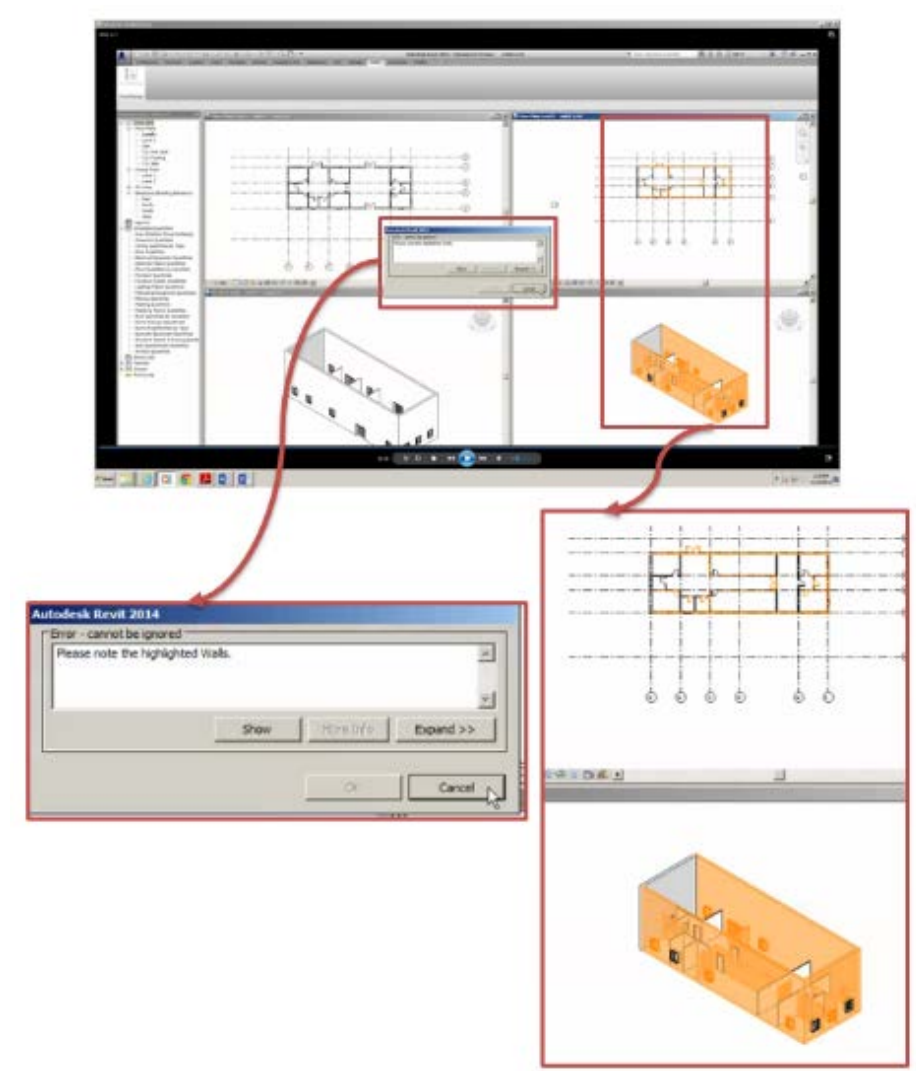

Figure 4: Change Ripple Effect Visualization

For example, the components that stay the same in both models after applying the owner's design changes appear in one color, and the components that exist in both models, but whose specifications are changed in the copy model, are indicated in another color. The components that are in the Original model and not in the Copy model are visualized in another color in the Original model.

The add-In can also provide a report of the changes detected after the component-by-component comparison. After the user applies the Check Change command, the model provides the change ripple effect visualization as well as a report. The report presents its information side-by-side; one side is for the Original model, and the other is for the Copy model, modified according to the design change requirements. The comparison model provides a report that shows all of the components that are changed due to the first source of change, the owner's design changes. The components that have some modification in their specification will get a check sign in the report. By looking at the report, the user can observe that the reason for a change in a component could be due to a change in the height, width, length or a change in the material of that component. A sample of this report is given in Figure 5.The report and the visualizing process do not yet work together; the user would get either the report of the impacted components or a visualization of the change ripple effect. This study proposes to make a connection between the report production and the ripple effect visualization, so that the user would be able to see both at the same time and in the same interface after applying the Check Change command. In addition, the user would be able to click on a component in the report to highlight that component in every view of the model: plan, 3D, elevation or section. The user (and other interested parties) would thus be able to understand and appreciate the implications of the change ripple effect much easier. 


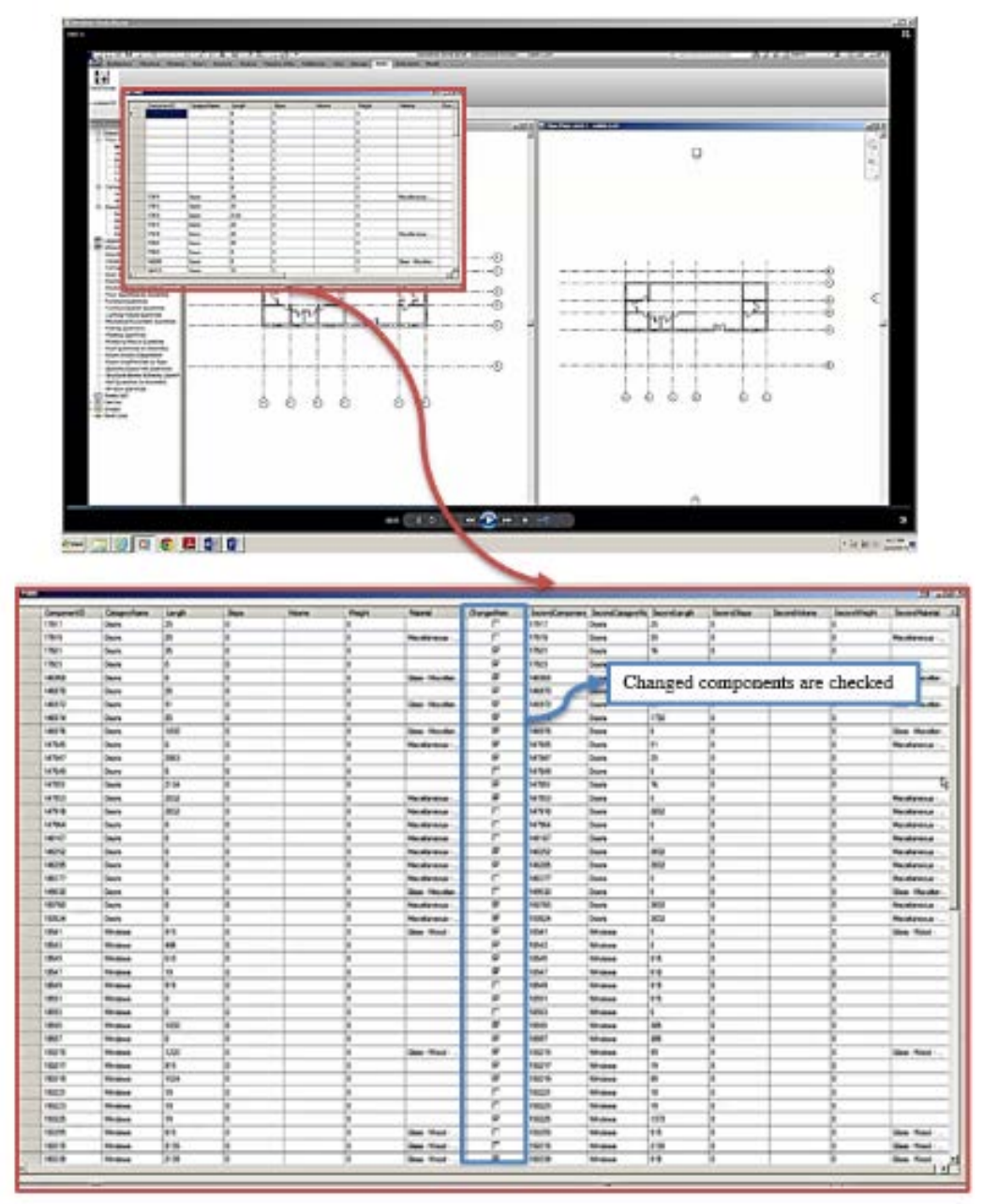

Figure 5: Report of the Impacted Components

\section{CONCLUSION}

Design changes initiated by owners are common and they can impact project's cost, time, quality and overall performance. A single change in one location in a project can easily cause a series of changes in other parts of the project. Finding the sequence of change or change path via 2D drawings is timeconsuming and demanding, and the result might not be accurate enough. This paper presents an automated BIM-based model to visualize the ripple effect of owner-requested design changes as they are applied to a project after the design phase has finished and before the construction phase has started. The developed model uses a component-by-component (ID-to-ID) comparison technique between the original model and the modified model to extract the list of affected components and highlight them in the Copy BIM model. The model is expected to allow project owners to make better decisions after being presented with the ripple effect of their requested changes in the architectural, mechanical, electrical and HVAC systems of the project.

\section{References}

Arain, Faisal Manzoor. 2008. "IT-based approach for effective management of project changes: A change management system (CMS)." Advanced Engineering Informatics 457-472. 
Autodesk. 2010. Sustainable Design Analysis and Building Information Modeling. Autodesk. http://images.autodesk.com/adsk/files/sustainable_design_analysis_and_building_information_modeli ng_white_paper.pdf.

Awad S. Hanna., P.E., M.ASCE, Lotfallah, Wafik B., and Min-Jae Lee, S.M.ASCE. 2002. "StatisticalFuzzy Approach to Quantify Cumulative Impact of Change Orders." JOURNAL OF COMPUTING IN CIVIL ENGINEERING 252-258.

Behzad Pilehchian Langroodi., Sheryl STAUB-FRENCH. 2012. "Change Management with Building Information Models: A Case Study." Construction Research Congress 2012. ASCE.

Dellon, Alferd L. 1986. "The Role of the Cost Engineer and the Change Order Process." American Association of Cost Engineers Transactions 232.

Hallock, B. 2006. "Managing change vs. administering the change order process." Nielsen-Wurster Communique 1.6.

Ibbs, C. W., Lee, S., and Li, M. 1998. "Fast-tracking's Impact on Project Change." Journal of Project Management 29 (4): 35-41.

Ibbs, C. William. 1997. "Quantitative Impacts of Project Change: Size Issues." Journal of Construction Engineering and Management 123 (3): 308-311.

Ibbs, C. William. 1997. "QUANTITATIVE IMPACTS OF PROJECT CHANGE: SIZE ISSUES." JOURNAL OF CONSTRUCTION ENGINEERING AND MANAGEMENT 308-311.

Koskela, L. 1992. Application of the new production philosophy to construction. Technical Report \# 72, Department of Civil Engineering, Stanford University, Center for Integrated Facility Engineering.

Ming Sun, Andrew Fleming, Sepani Senaratne, Ibrahim Motawa and Mei Lin Yeoh. 2006. "A Change Management Toolkit for Construction Projects." Architectural Engineering and Design Management 2: 261-271.

Mirshekarlou, Babak Rahmani. 2012. "A TAXONOMY FOR CAUSES OF CHANGES IN CONSTRUCTION." Master Thesis, Department of CIVIL ENGINEERING, THE MIDDLE EAST TECHNICAL UNIVERSITY.

Mokhtar, A., Bedard, C., and Fazio, P. 1998. "Information model for managing design changes in a collaborative environment." Journal of Computer and Civil Eng 12 (2): 82-92.

Osama Moselhi, Ihab Assem, and Khaled El-Rayes. 2005. "Change Orders Impact on Labor Productivity." JOURNAL OF CONSTRUCTION ENGINEERING AND MANAGEMENT 354-259.

Osama Moselhi., Charles Leonard., Paul Fazio. 1991. "Impact of change orders on construction productivity." Can. J. Civ. Eng. 484-492.

Porter, M.,. 2003. "The Economic Performance of Regions." Regional Studies 37 (6-7): 545-546.

Tigon, Robert L.K. 1990. "Effective controls for Large Scale Construction Projects." Project Managment Journal 21.

Tiong, R. 1990. "Effective Controls for Large Scale Construction Projects." Journal of Project Management 11 (1): 32-42.

Undurraga, M. 1996. Construction productivity and housing financing. Mexico: Seminar and Workshop, Interamerican Housing Union, Ciudad de Mexico Workshop, Interamerican Housing Union, Ciudad de Mexico,.

Voropajev, Vladimir. 1997. "Change management--A key integrative function of PM in transition economies." International Journal of Project Management 16 (1): 15-19. 